\title{
Fracture Mechanics on Aluminum Specimens
}

\author{
Juan Jose Mejia Briseno' ${ }^{1}$, Francisco Casanova-del-Angel ${ }^{2}$ \\ ${ }^{1}$ Tecnologico Nacional de Mexico, Instituto Tecnológico de Pachuca, Pachuca Estado de Hidalgo, Mexico \\ ${ }^{2}$ Seccion de Estudios de Posgrado e Investigación, Escuela Superior de Ingeniería y Arquitectura, Unit. Adolfo Lopez Mateos \\ Instituto Politécnico Nacional, Ciudad de México, Mexico \\ Email: itp20@hotmail.com, fcasanova49@prodigy.net.mx
}

How to cite this paper: Briseno, J.J.M. and Casanova-del-Angel, F. (2021) Fracture Mechanics on Aluminum Specimens. World Journal of Mechanics, 11, 237-257. https://doi.org/10.4236/wjm.2021.1112016

Received: November 11, 2021

Accepted: December 24, 2021

Published: December 27, 2021

Copyright $\odot 2021$ by author(s) and Scientific Research Publishing Inc. This work is licensed under the Creative Commons Attribution International License (CC BY 4.0).

http://creativecommons.org/licenses/by/4.0/

\section{(c) (i) Open Access}

\begin{abstract}
ASTM standards for A413 aluminum alloy specimen assays were used based on standard E399-05, with a minimum requirement of three specimens. Linear elastic fracture mechanic testing was carried out in plane strain conditions and fracture toughness of the tested aluminum, critical stress intensity factor was determined. Four specimens with the selected geometry were made, since in the pre-cracking process a non-acceptable propagation of crack may be present, i.e., the crack does not propagate in a parabolic manner. In like manner, the Type SE (B) specimen, that is, a beam subject to bending under a monotonic load, was used. Stress efforts were induced in the experiment, the load mode for such experiments is mode I, determining a temporary value of the $\mathrm{K}_{\mathrm{Q}}$ apparent stress intensity factor. When such value complies with the validity criteria of E-399 Standard, it becomes the stress intensity factor $\mathrm{K}_{\mathrm{IC}}$ of material.
\end{abstract}

\section{Keywords}

Metallography, A413 Aluminum, Fracture Mechanics, Stress Efforts, Fractography

\section{Introduction}

As it is well known, fracture mechanics resulted from the lack of adaptation of design criteria commonly used, based on criteria of plasticity, when they are used to estimate the strength of some structures. Therefore, at the end of the $19^{\text {th }}$ Century and the beginning of the $20^{\text {th }}$ Century, many well-known catastrophic failures occurred; particularly in vessels under pressure and in railroad equipment. The creation of fully welded structures during the Second World War led to a dramatic series of accidents. Failures occurred due to low plastic strain and low stress levels Ref. [1]. 
Fracture mechanics is not considered in structural design since, for every structural designer, not a single part of the structures should be fractured. Currently, it is generally accepted that every study carried out in fracture mechanics is made posteriori the manufacture of structures, i.e., when the first problems might have been studied a priori appear. In general, the growth of a crack is stable for a certain period, i.e., progressive load increases are required to cause progressive increases of the crack's length. Such periods may vary or even be inexistent, and it depends on the features of the problem. Even though the stable growth period is also the object of study in fracture mechanics, the ultimate purpose of fracture mechanics is to characterize unstable growth where the crack propagates continually under constant load, resulting in catastrophic and sudden failure of the structure.

In order to obtain $K_{I C}$ values, we relied on linear elastic fracture mechanics (LEFM), carrying out bending tests on specimens dimensioned under the testing ASTM E399-05 standard, ref. [2], and the B-645 testing practice. Specimens under study show the same geometry, with variation of thickness $B$ and, consequently, the size of the specimen, therefore generating the line of study on the range of variable thicknesses to obtain values of the $K_{Q}$ apparent stress intensity factor and assess them to determine the critical stress intensity factor $K_{I C}$ in mode $I$.

This type of aluminum is a material mainly used in the automotive, aerospace, and aeronautic industries. In those areas, the behavior to crack of a structural A413 aluminum casting has been studied. This aluminum alloy has a casting structure whose principal components are aluminum (Al) and silicon ( $\mathrm{Si}$ ); the latter is a chemical element giving the alloy special mechanic properties and high tensile strength.

Damage tolerance is defined as the ability of a structure to sustain static and/or cyclic loads derived from its service life and is caused by fatigue, environmental conditions and/or accidental causes, until such damage may be detected through inspection. The purpose of inspections is to detect damage before it reaches a critical size, at which the structure may not bear loads, therefore resulting in structural failure, ref. [3].

Most dangerous failure events in structures under loads are related to facture. These occur when an external load exceeds the failure strength of the material. The relation between load and strength of a material is strongly influenced by the presence of defects, among which the crack type imperfection is the most harmful, ref. [4]. Recent economic studies in various countries reveal that the estimated annual cost of component fracture occurrence reaches approximately $4 \%$ of the Gross Domestic Product of a country. In Mexico, its approximate cost is more than 46,000 million dollars, ref. [5].

A problem of the light alloys during casting manufacture is pores and shrinkage. These affect the mechanical behavior of the component since they damage its mechanical properties. It is important to know these variables in order to predict both the residual strength and the damage tolerance, since by applying 
fracture mechanics such deterministic results are obtained. In order that a structure may reach the end of its design in a safe manner, there has to be an iteration between the design and the assay, as well as between manufacture and inspection throughout its useful life.

\section{Experimental Methodology}

The hypothesis is that the smaller the specimen, the higher the fracture toughness of the aluminum casting. The purpose is to determine the effect of specimen size on fracture toughness in A413 aluminum alloy specimens in casting conditions.

In order to obtain the dimension of geometry chosen, in accordance with ASTM E399-05, ref. [2], mechanical properties of the material were analyzed: the ultimate yield strength and critical stress intensity factor. Once the dimension has been determined, the scaling of dimensions is made in order to obtain a variation of the specimen size, whose factor is relevant in this study since the behavior of the size effect is to be found. From these three families of specimens have been derived as follows: big, EG, medium, G, and small, M: $E G(1,2,3$ and 4); $G$ (1, 2, 3 and 4); and $M(1,2,3$ and 4), respectively. The measurements of the $M$ specimens are $1.8 \mathrm{~cm}$ by $2.2 \mathrm{~cm}$. The M5 sample was removed to maintain a constant in the number of samples per family. The material used is an A413 aluminum-silicon casting alloy type, in ingots to be used for casting. The main component is silicon ( $\mathrm{Si}$ ). The effect of silicon in aluminum alloys is that it improves the casting properties of aluminum. The most important are: yield, increase of mechanical strength and corrosion resistance. The chemical elements of A413 alloy are alloy-forming and improve the properties of such alloys: iron $(\mathrm{Fe})$, whose presence modifies the silicon phase where the most common are alpha and beta phases. The aluminum-silicon alloys, manufactured by casting, have particularly low Fe levels to avoid adhesion of the piece to the die, with a percentage of $1.5 \%$ to $2 \%$ in weight. Magnesium (mg) is added to give resistance to the alloy, which creates silicon-magnesium precipitates $\left(\mathrm{Mg}_{2} \mathrm{Si}\right)$ in the matrix. Copper $(\mathrm{Cu})$ increases mechanical resistance of the alloy. Manganese $(\mathrm{Mn})$ produces solubility of $\mathrm{Fe}$ and $\mathrm{Si}$ in aluminum and alters the composition and morphology of primary phase constituents of Al-Fe-Si composite.

The dimensions and orientation of specimen's for extraction of specimens from ingot for tensile and fracture mechanics testing are shown in Figure 1.

\subsection{Metallography of Specimen's for Mechanical Tests}

In order to identify the microstructure and quantification of pores of aluminum casting, a metallographic preparation was made. It consisted in cutting the samples with an abrasive disc cutter while supplying coolant to avoid altering the sample. It was cut and mounted in Bakelite for better handling and storage. Mounting on Bakelite was made in a mounter, and consisted in heating the Bakelite resin and the sample up to $170^{\circ} \mathrm{C}$ for 15 minutes at a 1000 PSI (69 bar) 


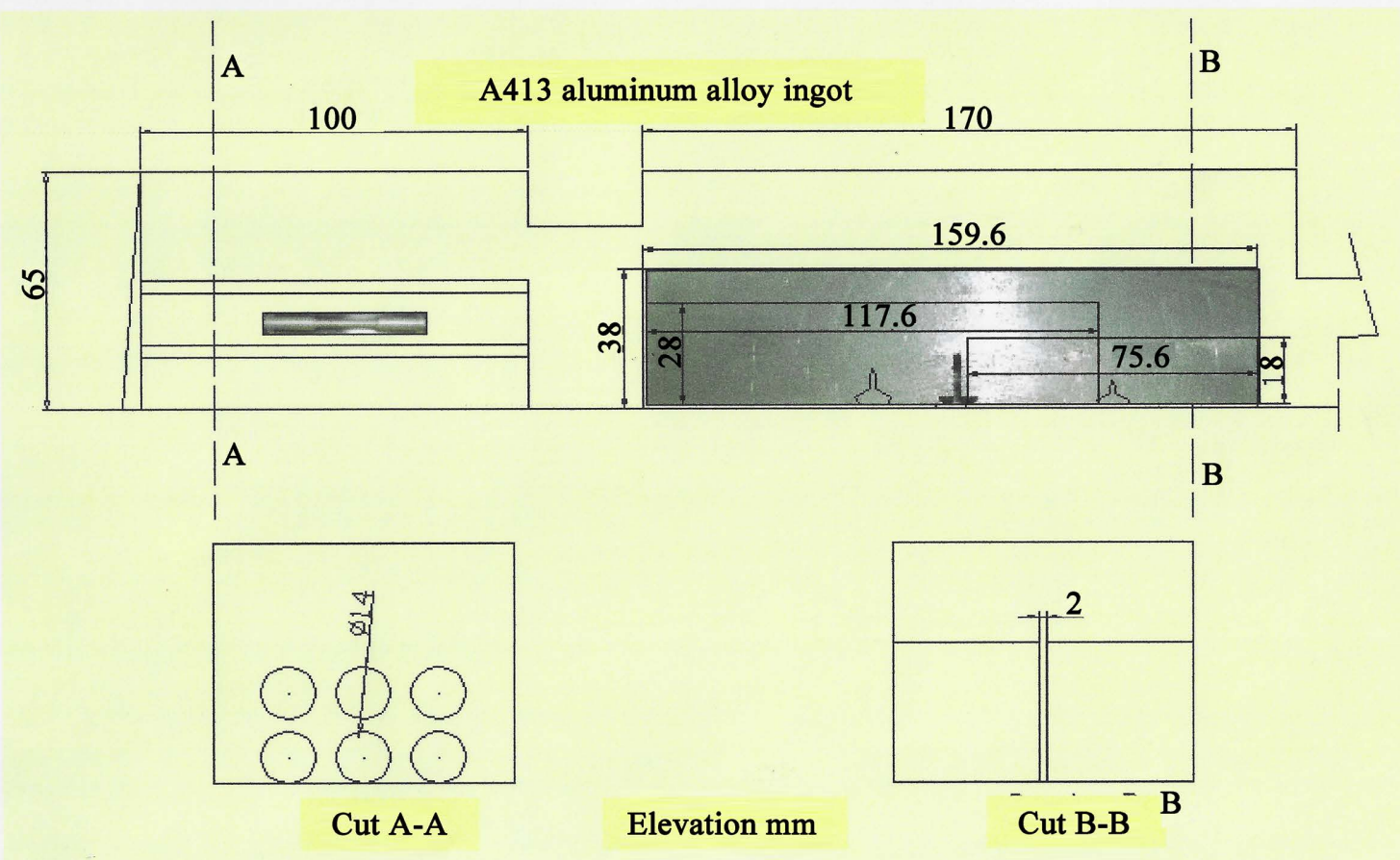

Figure 1. Orientation and sectioning of specimen's, mechanical tests.

pressure. Then, it was cooled recirculating water down to a temperature of $30^{\circ} \mathrm{C}$. Afterwards, the material's surface was prepared for its first phase, called rough grinding, where the surface of the sample was improved with sandpaper in a uniform manner, gradually reducing the size of the grain. In this work, sandpaper from 100 through to 1200 was used. During the sandpaper change, the sample was rotated $90^{\circ}$. At the beginning of the second polishing phase, called fine grinding, a smooth flat surface is required and obtained with a moistened spinning wheel covered with a special cloth with abrasive particles carefully chosen according to their size. Mirror polishing was made with alumina with particle sizes of $1,0.3$ and 0.05 micrometers. Figure 2 shows five samples built for metallography. Here, a chemical attack to samples was made with a $\mathrm{NaOH}(\mathrm{NaOH}$ 6 gr in $\mathrm{H}_{2} \mathrm{O} 50 \mathrm{ml}$ ) solution for three seconds and then with a $0.5 \% \mathrm{HF}$ (3 drops of $\mathrm{HF}$ in $\mathrm{H}_{2} \mathrm{O} 50 \mathrm{ml}$ ) solution for three minutes, ref. [6].

\subsection{Tensile Test and Geometry of Specimen's}

The tensile test was made in accordance with ASTM B557M-15 standard, ref. [7], a normalized testing method for casting materials, aluminum casting and magnesium alloys. The test included applying stress on a specimen with a previously chosen geometry. Stress was applied in a monotonic manner (increased at a constant speed), up to failure of specimen.

Five short standard specimens with no thread were manufactured, with the dimensions shown in Table 1, geometry is shown in Figure 3.

The specimen was manufactured in accordance with the standards, and the maximum load for the assay was determined at $8.14 \mathrm{kN}$. The test speed of the 


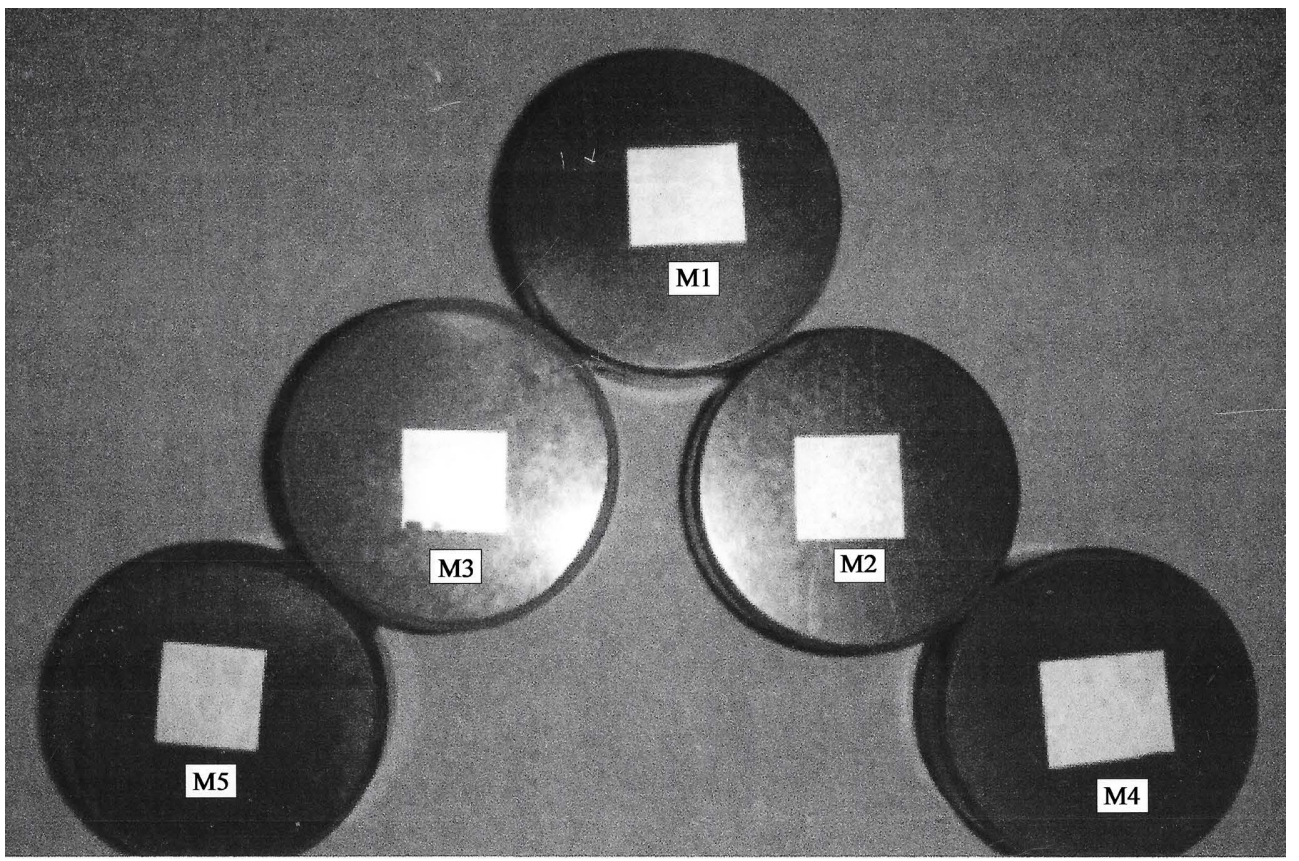

Figure 2. Five samples for metallography for tensile test.

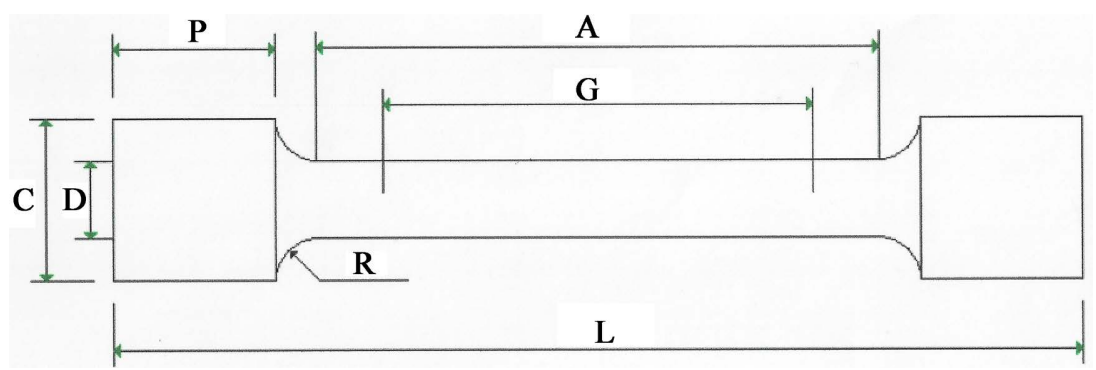

Figure 3. Specimen for tensile test.

Table 1. Measurements of probe for tensile test.

\begin{tabular}{cc}
\hline Description & Measurementunit (mm) \\
\hline Calibratedlength (G) & 30 \\
Diameteroflenght (D) & 6 \\
Notchradius (R) & 6 \\
Reducedsectionlength (A) & 36 \\
Test tubelength (L) & 110 \\
\hline
\end{tabular}

specimen ranged between 0.031 and $0.033 \mathrm{kN} / \mathrm{s}$.

Five standard specimens were obtained for tension, round cross section, Figure 3. Once these were obtained, they were assayed in an Instron ${ }^{\circledR} 8801$ servohydraulic machine with a $100 \mathrm{kN}$ load cell. The machine has interchangeable 100 $\mathrm{kN}$ and $10 \mathrm{kN}$ load cells. Uniaxial traction tests were made in the load control mode at a $0.033 \mathrm{kN} / \mathrm{s}$ speed and the starting length to measure elongation was four times the $6 \mathrm{~mm}$ diameter of the specimen, in accordance with the proce- 
dure specified by ASTM B557M-15 standard, ref. [7]. The types of sections used in specimen are round and symmetric regarding their longitudinal axis to avoid bending during the assay, Figure 4.

Figure 5 shows the flow chart designed for tests carried out in order to obtain

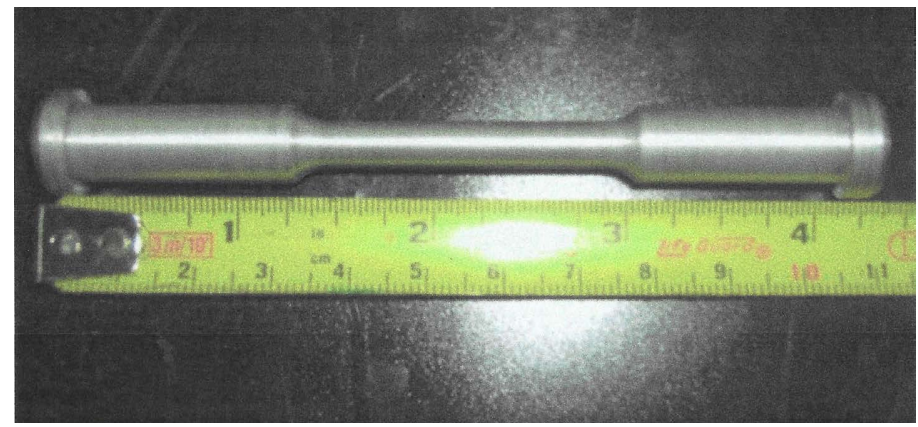

Figure 4. Specimen for tensile tests, round cross section type.

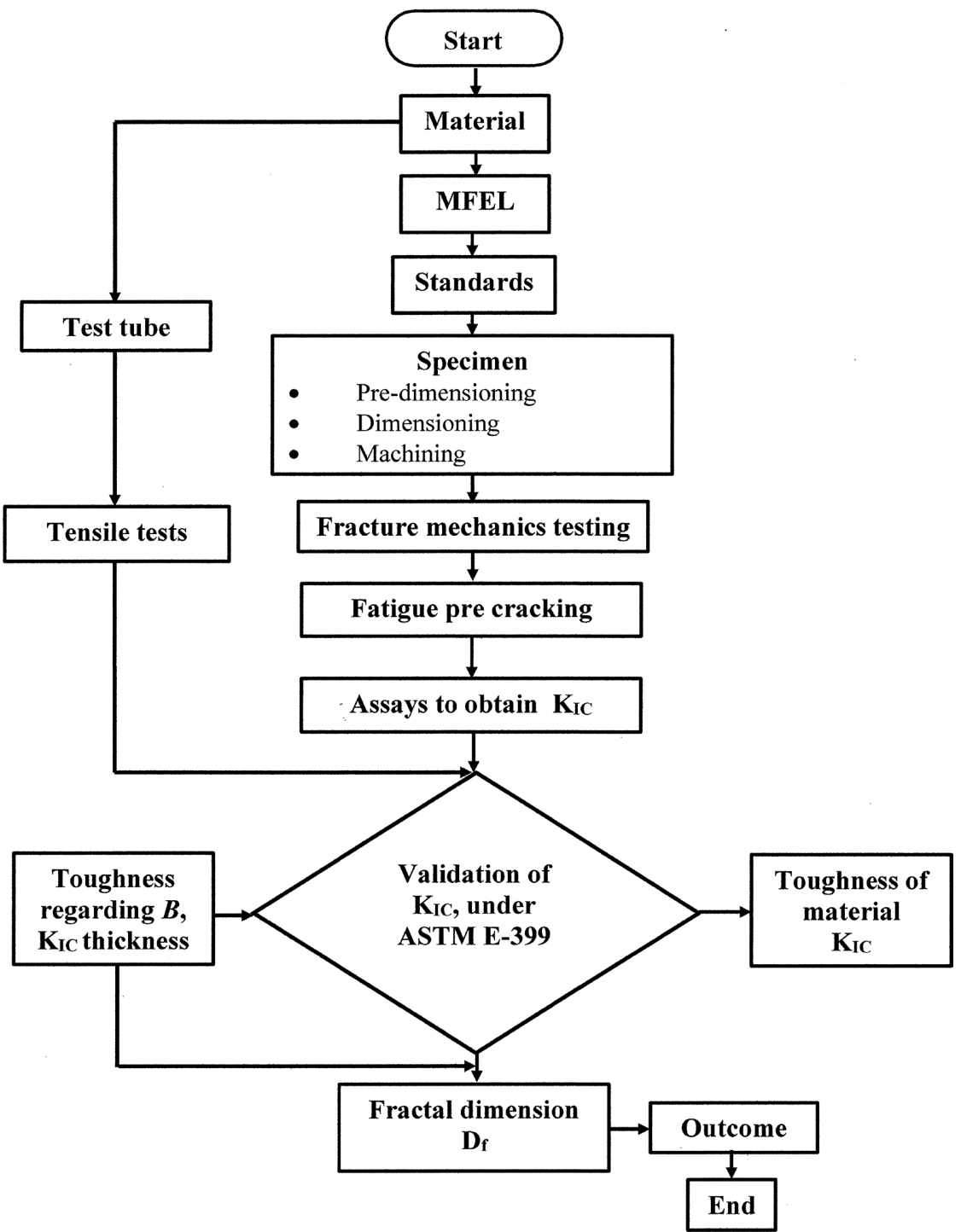

Figure 5. Flow chart of the experiment. 
mechanical properties and analyze the effect of the size of the specimen in $K_{I C}$ fracture toughness.

There is an interesting document that considers three kinds of combined loads which are gravity, fracture water pressure and seismic force, constructs a unstable rock mechanics model and it uses a fracture mechanics method to deduce the composite stress intensity factor of the type I-II, ref. [8].

\subsection{Use and Scope of ASTM E399 Standard}

ASTM E399-05 and ASTM B645-10 standards were used to carry out the assays for A413 aluminum alloy specimens, ref. [2] [9]. In this assay method, $K_{I C}$ resistance to fracture of metallic materials in plane and elastic-linear strain, with fatigue pre-cracking conditions of samples $1.6 \mathrm{~mm}$ (0.063 inches) or higher thickness were determined. Such testing method is divided into two parts. The first one gives general information regarding general recommendations and demands for $K_{I C}$ tests. The second part includes requirements in accordance with the annexes providing specific information on the displacement measurement and the design for load fixing, procedures for fatigue cracking, and the special requirements for several specimen configurations reached by the testing method.

Variation in $K_{I C}$ value was expected within the allowed range of sample proportions, $a / W$ and $W / B$. Residual stresses may negatively affect the value of the stress intensity factor $K_{Q}$, and this effect may be particularly significant, since the testing method involves requirements to assess $K_{Q}$ obtained in the tests.

ASTM B645-10 standard is a supplement to E399-05 standard, ref. [9] [2], it provides the feature to determine resistance to fracture in plane strain, and may be used as a supplement to the E-399-05 method, ref. [2]. Application of this practice is mainly used to guarantee quality and release of materials in valid plane strain cases.

The type of specimen used is a SEB beam based on ASTM E399-05 standard, ref. [2], which provides the requirements for the type of specimen, and is used for the fracture mechanics testing, since the required support devices are available. Configuration of specimens is based on Section VII of the standard.

\section{Dimensioning Specimens for Tensile Tests}

The size of specimen required for the test is based on the square of the relation between toughness $K_{I C}$ and the yield point of the material $\sigma_{Y S}$ under a constant of 2.5. The minimum thickness required by ASTM E399-05 standard was pre-dimensioned for fracture toughness testing, ref. [2]. Such standard establishes Equation 1 for minimum $B$ width.

$$
B, a \geq 2.5\left(\frac{K_{I C}}{\sigma_{Y S}}\right)^{2}
$$

From the tensile test is obtained the yield strength of the material $\left(\sigma_{Y S}=82.0\right.$ $\mathrm{MPa})$. Yield strength for aluminum A413 aluminum $\left(\sigma_{Y S}=130.0 \mathrm{MPa}\right)$ has also been reported by various aluminum suppliers. With the yield stress obtained 
from the test $\left(\sigma_{Y S}=82.0 \mathrm{MPa}\right)$ is obtained thickness $B=37.18 \mathrm{~mm}$, rounded off to $38.00 \mathrm{~mm}$. For variation of size of the specimen with the yield stress value reported $\left(\sigma_{Y S}=130.0 \mathrm{MPa}\right)$, a minimum $B=14.79 \mathrm{~mm}$ thickness is obtained, rounded off to $18.00 \mathrm{~mm}$.

Based on the available length given by the material and the minimum thickness required by the E-399-05 standard for the SEB beam dimension, ref. [2], a $38 \mathrm{~mm} B$ thickness was established. On the other hand, we have that 2.1 of $W$ is equal to $L / 2$, if $W$ is equal to $B$ for a rectangular section, we obtain that length $L$ is equal to $159.6 \mathrm{~mm}$, from which the other dimensions of the specimen were determined. Geometry is shown in Figure 6.

Since dimensions of the specimen were determined in accordance with the ASTM E399-05 standard [2], EG was assigned mnemotechnically to identify the large specimen. In order to know the effect of specimen size, three different sizes were obtained, called large $(E G)$, medium $(G)$ and small $(M)$. Table 2 shows nomenclature, size and size ratio regarding the specimen.

\subsection{SEB Type Specimens}

Specimens were manufactured from the largest to the smallest size and/or dimension, i.e., the large $E G$ size was machined. After fatiguing and fracturing that specimen, two sections were obtained from the original specimen. From these sections, the size of specimen $M$ was obtained, which is the smallest. The medium specimen $G$ was manufactured with material without residual load effects, in order to know the effect of specimen size in fracture toughness.

\subsection{Propagation of Fatigue Cracks}

Fatigue is defined as the permanent, progressive and localized cracking which occurs on a material subject to fluctuating cyclical stress and strain, with a maximum value lower than the tensile strength of the material. A requirement of fracture mechanics is that there must be a defect or crack in the material. A way to assess fatigue is through the fracture mechanics method, which allows the obtaining of data on propagation of fatigue cracks. Therefore, before starting assays on the specimen there must be a pre-existing crack. Propagation of fatigue cracks occurs in three well-defined regions, Figure 7, ref. [10]:

In order to obtain a crack with a sufficiently acute radius, the specimen was fatigue pre-cracked. The Instron servo-hydraulic machine was used to propagate
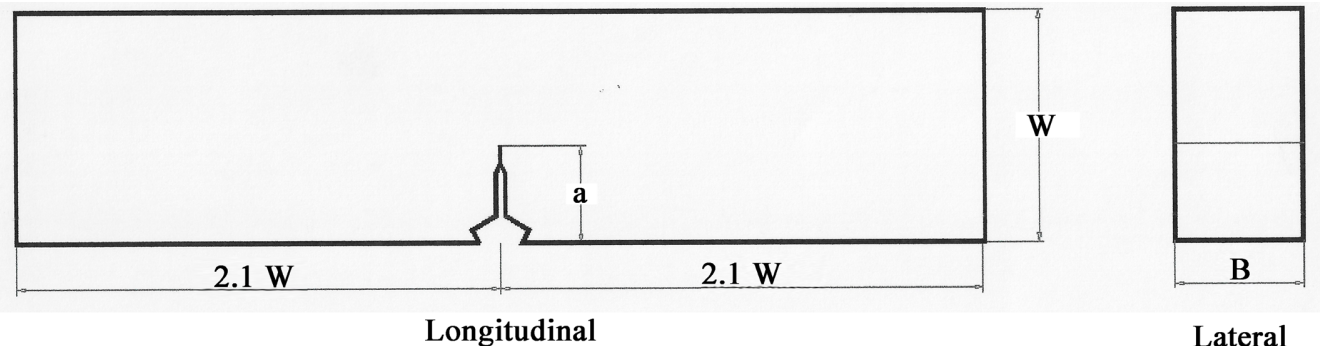

Lateral

Figure 6. SE (B) type specimen. 
Table 2. Geometries of specimens and dimensions.
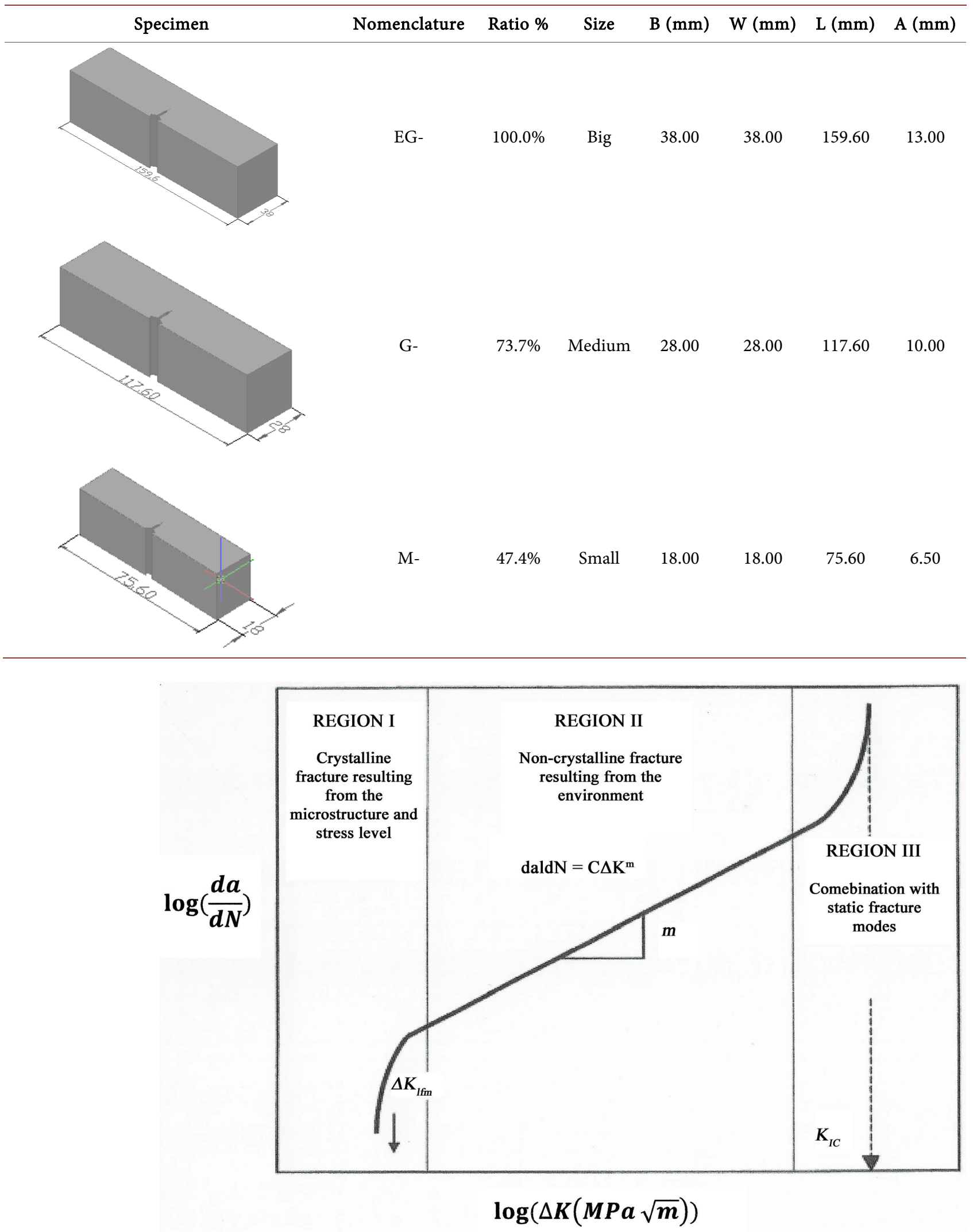

Figure 7. Typical behavior of fatigue crack growth in metals. 
the crack, in addition the $d a / d N$ software was used which allowed the fatiguing of the specimen up to the desired length. In the section of specimen parameters, the fields considered are: type of specimen and dimensions for each specimen, as well as the mechanical properties of the material: ultimate stress, $2 \%$ yield stress, and Young's module. Control parameters establish the crack method. Compliance was used for all specimens, with a constant $6.5 \Delta K$ and a $20 \mathrm{~Hz}$ frequency. Figure 8 shows application of the software and sinusoidal graphic.

\subsection{Fractography}

From the study of fracture surfaces (Figure 9 for the EG02 specimen), data on the fracture mechanisms was obtained. In order to identify fractures, a scanning electron microscope (SEM) was used. Once pictures were obtained with the SEM, the fracture surface was examined, which was used to identify the type and

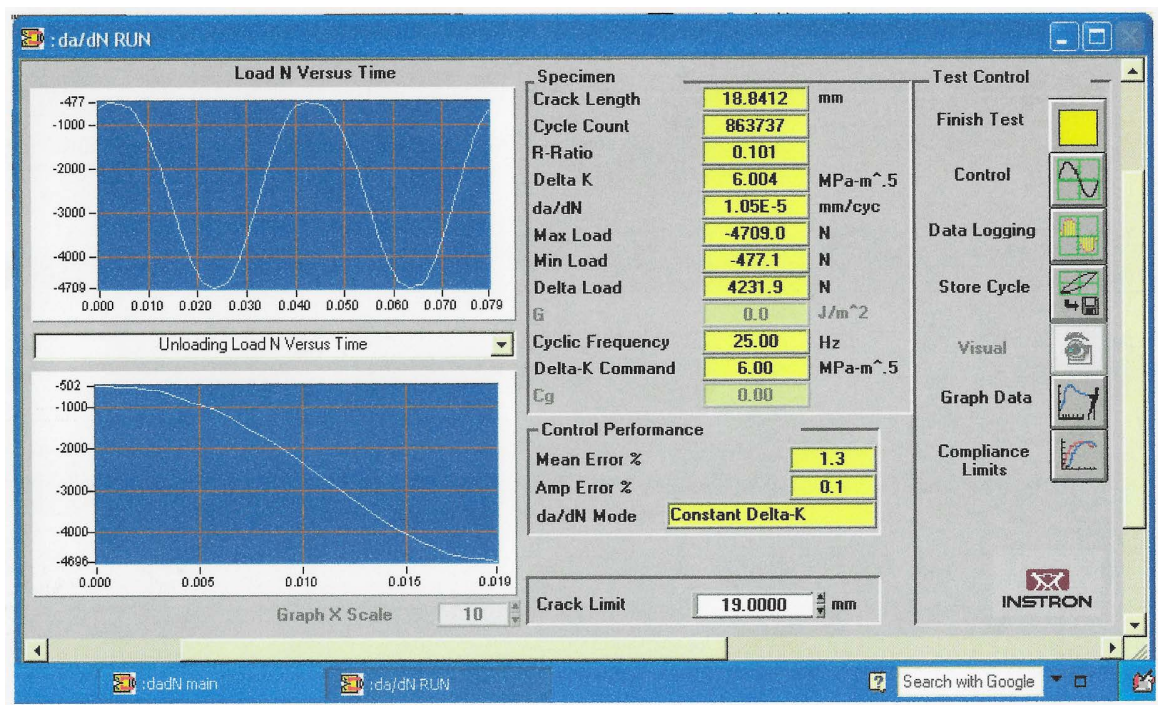

Figure 8. Fatigue process with software $d a / d N$, load $v s$ time graph, $20 \mathrm{~Hz}$ frequency.

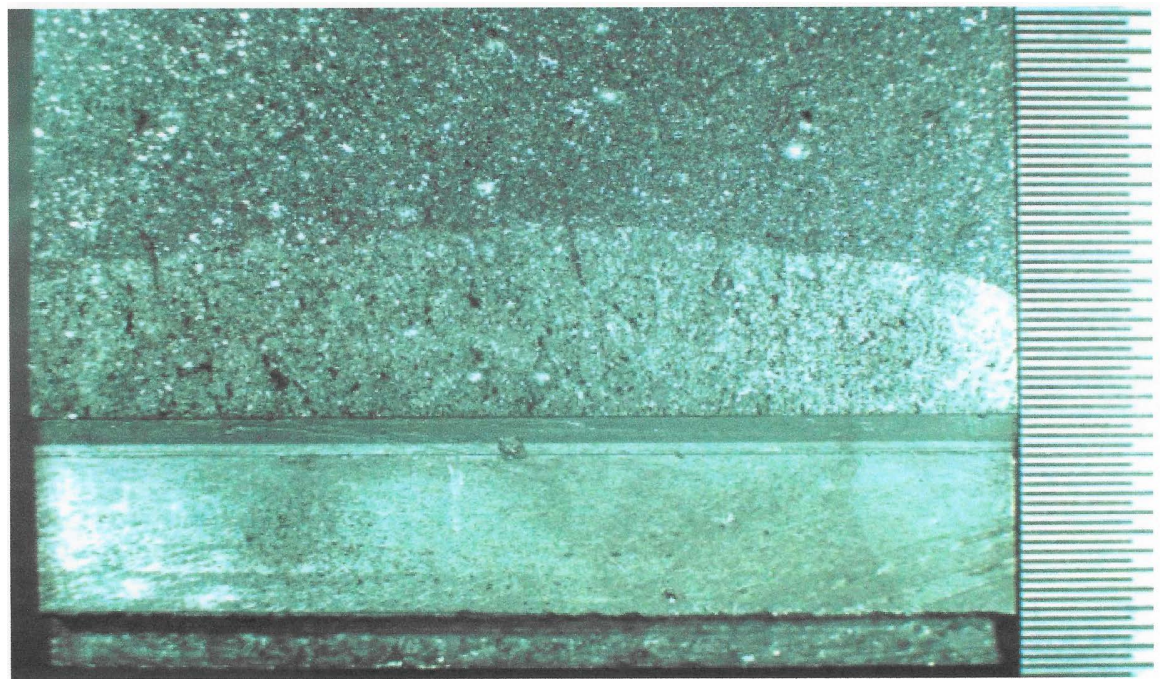

Figure 9. Failure face for fractography, EG02 specimen. 
mechanisms of the fracture.

\subsection{Pores Quantification}

As is well known, in casting processes, several defects may occur, depending on various factors such as material, design and processes. While some defects only affect appearance of the casting, others may have adverse effects on structural integrity. Several defects are developed upon processing of the material. This occurs particularly during the solidification process, causing porosity due to contractions or presence of gases. On fracture surfaces, holes due to pores may be observed by sight. This is why the study was carried out, in order to know if they impaired mechanical properties of the element.

Based on the metallography samples, photomicrography's were taken with $5 \times$ and $20 \times$ objectives in the Olympus PMG3 inverted metallurgical microscope, and were analyzed with Image Pro Plus software to determine the percentage of pores, Figure 10. Figure 11 shows the type of existing pores in the material studied with a $20 \times$ objective.

\section{Characterization of the Material}

The chemical analysis of the samples used in the experiment (extracted from A413 aluminum-silicon casting alloy ingots) allowed knowledge of the percentage of elements present in the alloy under study. In the microstructure analysis, there are three phases: magnesium, iron, and eutectic, $\mathrm{Mg}_{2} \mathrm{Si}, \mathrm{Fe}_{3} \mathrm{Si} \_\mathrm{Al12}$, and $\mathrm{Fe}_{2} \mathrm{Si}_{2} \_\mathrm{Al9}$. Chemical composition of A413 alloy, shown in Table 3, contains $11.66 \%$ silicon $(\mathrm{Si})$, main element of the alloy.

\subsection{Metallography of Samples Subject to Tensile Tests}

Techniques applied in ASTM E399-05 standard regarding preparation of the sample were used, ref. [2]. In order to identify each phase of the aluminum-silicon

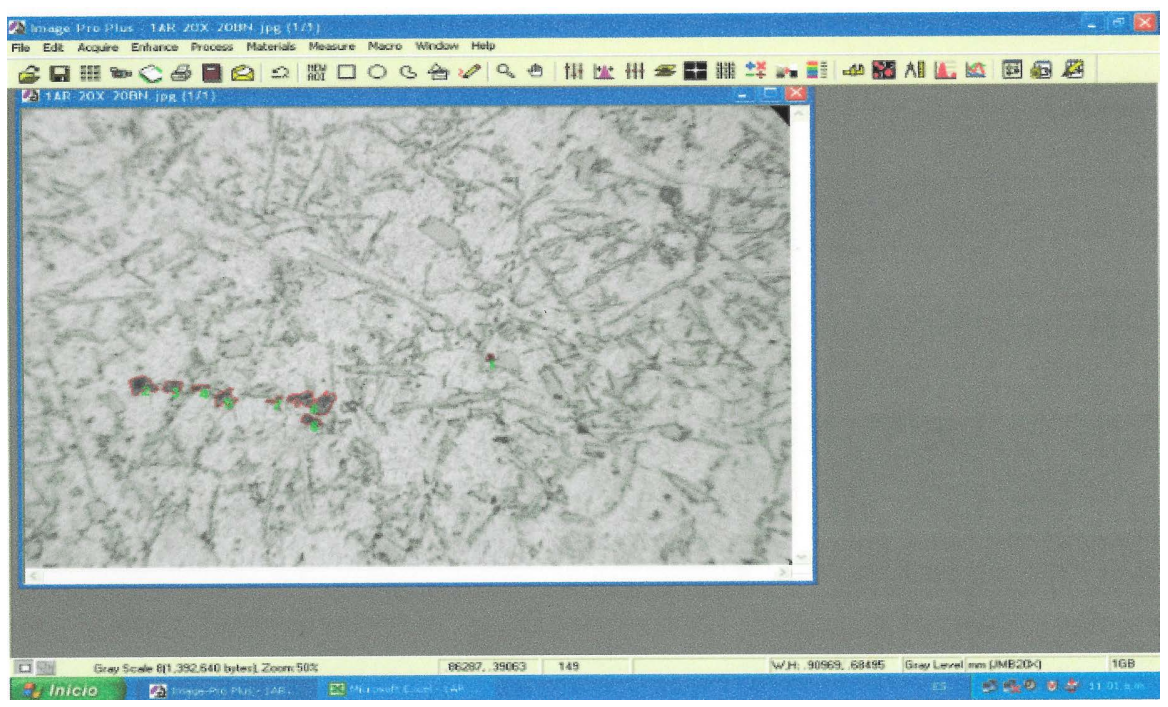

Figure 10. Image Pro Plus software to determine percentage of pores. 


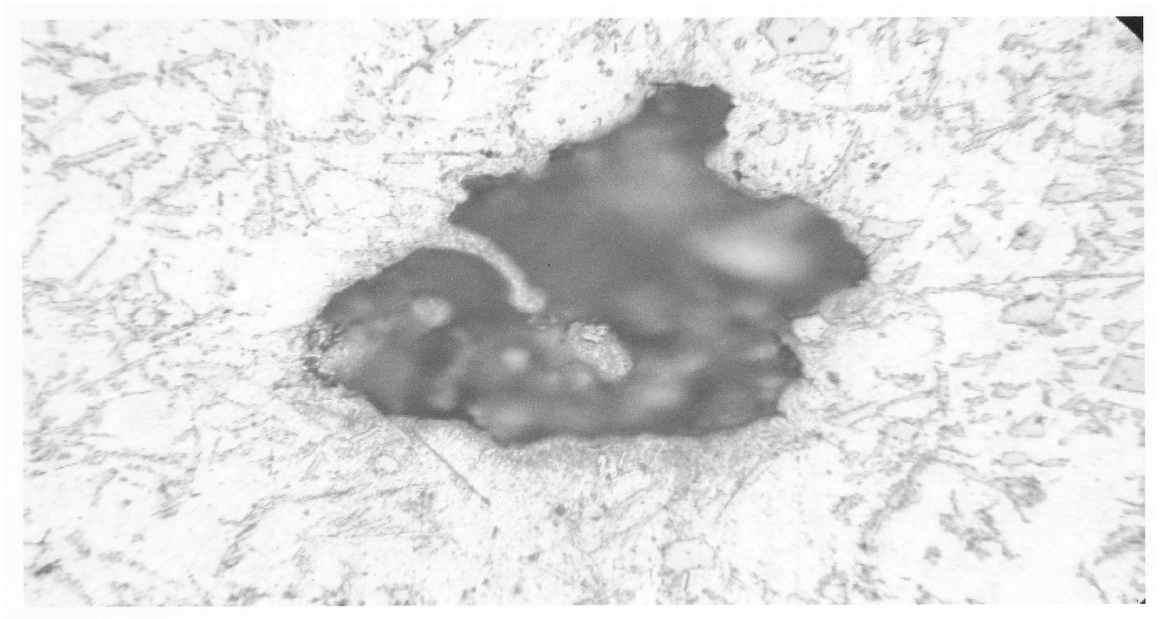

Figure 11. Existing the material studied, objective $20 \times$.

Table 3. Chemical composition of the sample.

\begin{tabular}{cc}
\hline Chemical element & $\%$ \\
$\mathrm{Si}$ & 11.66 \\
$\mathrm{Fe}$ & 0.63 \\
$\mathrm{Cu}$ & 0.33 \\
$\mathrm{Mn}$ & 0.07 \\
$\mathrm{Mg}$ & 0.10 \\
$\mathrm{Zn}$ & 0.06 \\
$\mathrm{Ni}$ & 0.01 \\
$\mathrm{Al}$ & Balance \\
\hline
\end{tabular}

alloy, an optical microscope connected to image analysis equipment was used. This identification was made through morphological comparison. Pictures were properly recorded at $100 \times$ to differentiate the various phases present, Figure 12 .

Figure 13 shows various precipitates and the ways phases are present, for $\mathrm{Mg}_{2} \mathrm{Si}$, in dark needles. For $\mathrm{Fe}_{3} \mathrm{Si} \_\mathrm{Al12}$, needles are homogeneous grey and for the eutectic phase $\mathrm{Fe}_{2} \mathrm{Si}_{2} \mathrm{Al} 9$ they are dark grey and well-defined.

\subsection{Tensile Tests}

In order to know actual mechanical properties of the A413 aluminum casting: ultimate stress, $\sigma_{U}, 2 \%$ yield stress, $\sigma_{Y S}$, and E Young's module of the material under study, it is necessary to carry out tensile tests for such case. These tests are crucial since from such data the specimens are dimensioned for fracture mechanics testing. The geometric design of tensile specimens was based on the ASTM B557M-15 standard, ref. [7], with a $6 \mathrm{~mm}$ diameter, and the relation for the length of the acceptance region was four times the diameter, in accordance with the standard. Five specimens were obtained, which were assayed in a servo-hydraulic machine (Instron 8801 ) with a $100 \mathrm{kN}$ load cell. Tests in uniaxial 


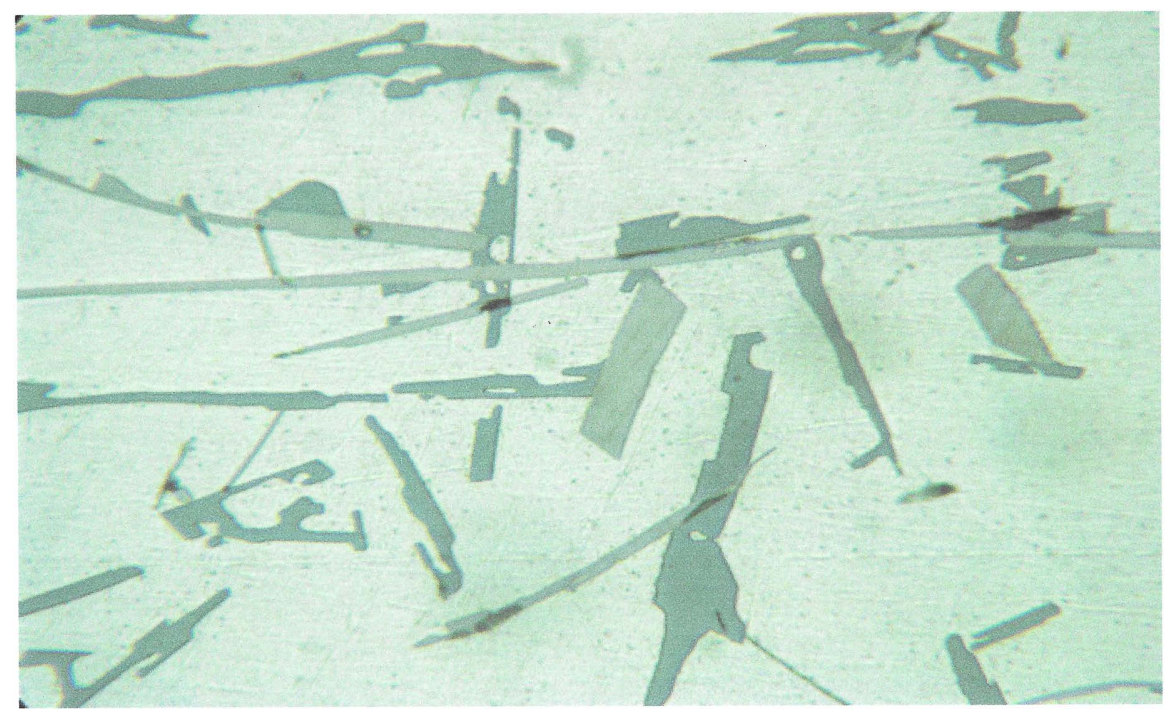

Figure 12. Microstructure of A413 alloy, objective 100×.

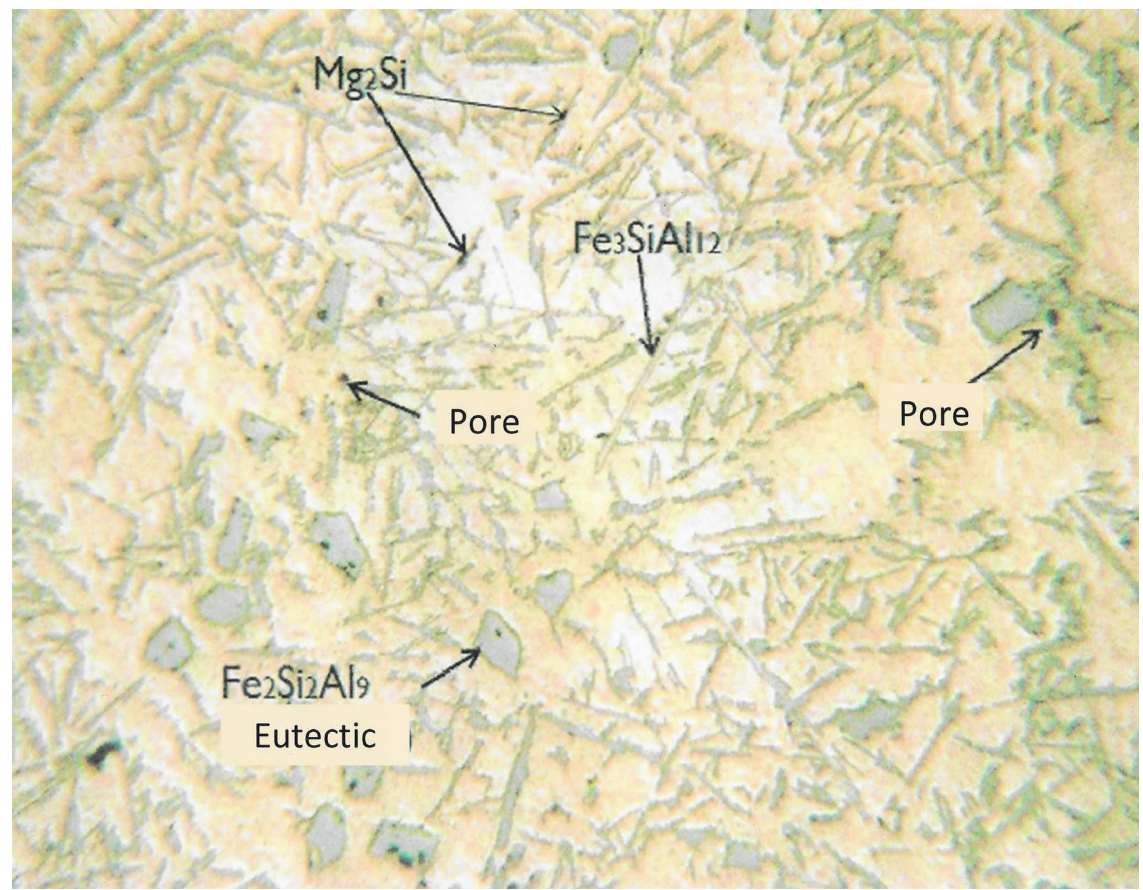

Figure 13. Typical microstructure of samples of an aluminum-silicon alloy.

traction were made in the load control mode at a $0.033 \mathrm{kN} / \mathrm{s}$ speed, in accordance with the procedure specified by the standard.

Figure 14 shows the stress-strain curves, well-defined by a straight line at the beginning (elastic linear range), followed by a curve, until reaching the maximum stress.

\subsection{Uniaxial Tensile Analysis}

Average values of mechanical properties are shown in Table 4. Variance percentages of the results obtained in the tensile tests were determined, and dispersion of 


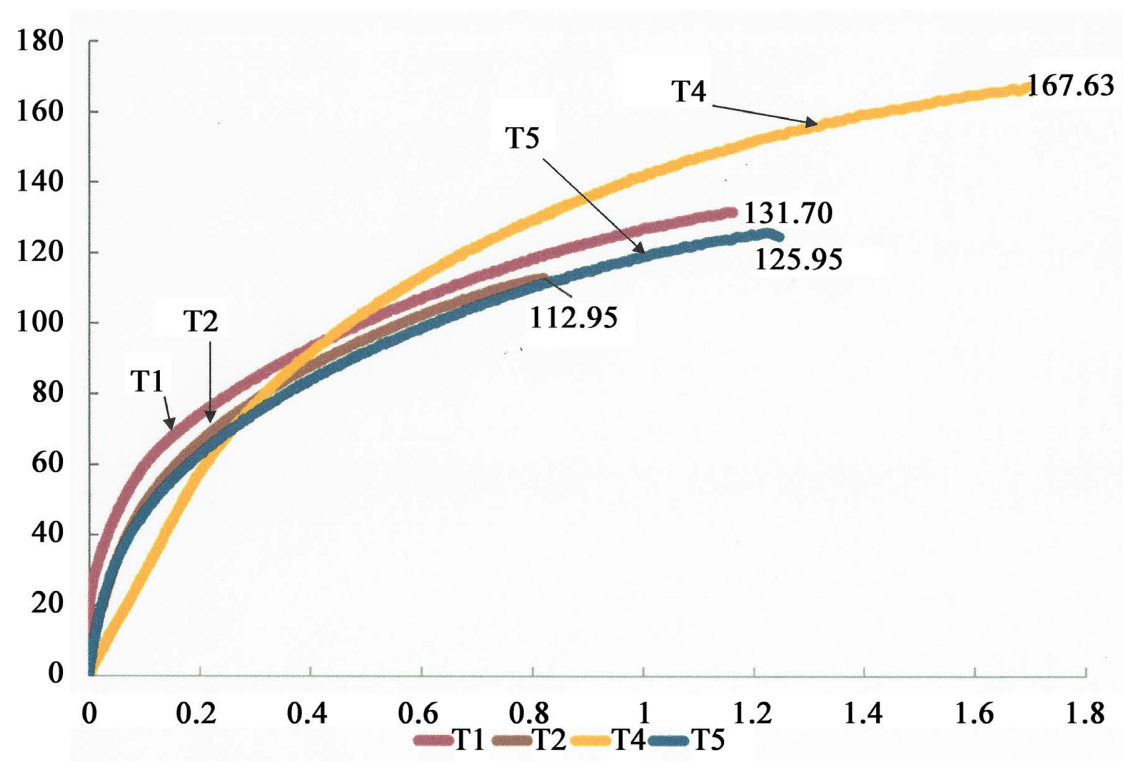

Figure 14. Stress vs strain curves, A413 aluminum alloy. (x \& y axis units are megapascals)

Table 4. Tensile mechanical properties of A413 aluminum.

\begin{tabular}{ccc}
\hline Test tube & $\boldsymbol{\sigma}_{Y S} \mathbf{M P a}$ & $\sigma_{U} \mathbf{M P a}$ \\
\hline $\mathrm{T} 4$ & 114.31 & 167.63 \\
$\mathrm{~T} 1$ & 90.89 & 131.7 \\
$\mathrm{~T} 5$ & 84.18 & 125.95 \\
$\mathrm{~T} 2$ & 80.34 & 112.95 \\
Mean & 92.43 & 134.56 \\
Standard deviation & 15.22 & 23.40 \\
\% C.V. & 16.47 & 17.39 \\
\hline
\end{tabular}

the yield stress and ultimate stress were observed. Variance coefficient percentages are $16.47 \%$ and $17.39 \%$, respectively. From five specimens, only one was not assessed; this was because it was outside calibrated length, and was thus rejected.

\section{Fracture Mechanics and Fracture Toughness Testing}

Results obtained from assays in the laboratory are shown in Table 5. The penultimate column shows validation of acceptance of $K_{I C}$. It can be observed how $K_{I C}$ decreases as the size of the specimen gets smaller.

Figure 15 shows the load vs crack opening displacement curves of standard, medium and small specimens.

\subsection{Load vs Displacement Curves}

Figures 16(a)-(c) show load vs crack opening displacement curves of specimens. The critical stress intensity factor was determined drawing a secant line 
Table 5. Results of fracture mechanics testing.

\begin{tabular}{cccccccccc}
\hline Specimen & $B(\mathrm{~mm})$ & $\boldsymbol{a}_{c}(\mathrm{~mm})$ & $\boldsymbol{a}_{c} / \mathrm{W}$ & $\boldsymbol{P}_{\max }(\mathrm{N})$ & $\begin{array}{c}K_{I C}(\mathrm{Mpa} \\
\left.\mathrm{m}^{1 / 2}\right)\end{array}$ & $\begin{array}{c}B>2.5 \\
\left(\mathrm{~K}_{\mathrm{IC}} / \sigma_{\mathrm{YS}}\right)^{2}\end{array}$ & $\boldsymbol{P}_{\max } / P_{Q} \begin{array}{c}\boldsymbol{\delta}_{K I C} \\
(\mathrm{~mm})\end{array}$ \\
\hline M2 & 17.70 & 10.54 & 0.59 & 1461.11 & 8.65 & 231.62 & 1.090 & 0.0122 \\
M3 & 17.63 & 10.25 & 0.57 & 1488.48 & 8.30 & 21.75 & 1.153 & 0.0112 \\
M4-EG2 & 18.00 & 9.64 & 0.54 & 1874.94 & 9.33 & 27.475 & 1.130 & 0.0141 \\
G1 & 27.195 & 14.18 & 0.51 & 4266.51 & 9.90 & 30.98 & 1.130 & 0.0159 \\
G2 & 27.78 & 15.77 & 0.56 & 3488.80 & 10.00 & 31.57 & 1.046 & 0.0162 \\
G3 & 27.61 & 16.05 & 0.57 & 3437.51 & 9.98 & 31.43 & 1.038 & 0.0162 \\
G4 & 27.90 & 16.01 & 0.57 & 3522.20 & 10.24 & 33.14 & 1.044 & 0.0171 \\
EG01 & 38.00 & 19.64 & 0.52 & 6967.47 & 10.64 & 35.73 & 1.286 & 0.0184 \\
EG02 & 38.11 & 21.32 & 0.56 & 6251.41 & 10.84 & 37.25 & 1.175 & 0.0192 \\
EG03 & 38.11 & 21.87 & 0.57 & 5920.14 & 10.80 & 37.02 & 1.222 & 0.0189 \\
EG04 & 38.11 & 21.48 & 0.56 & 5781.31 & 10.16 & 32.63 & 1.168 & 0.0168 \\
\hline
\end{tabular}

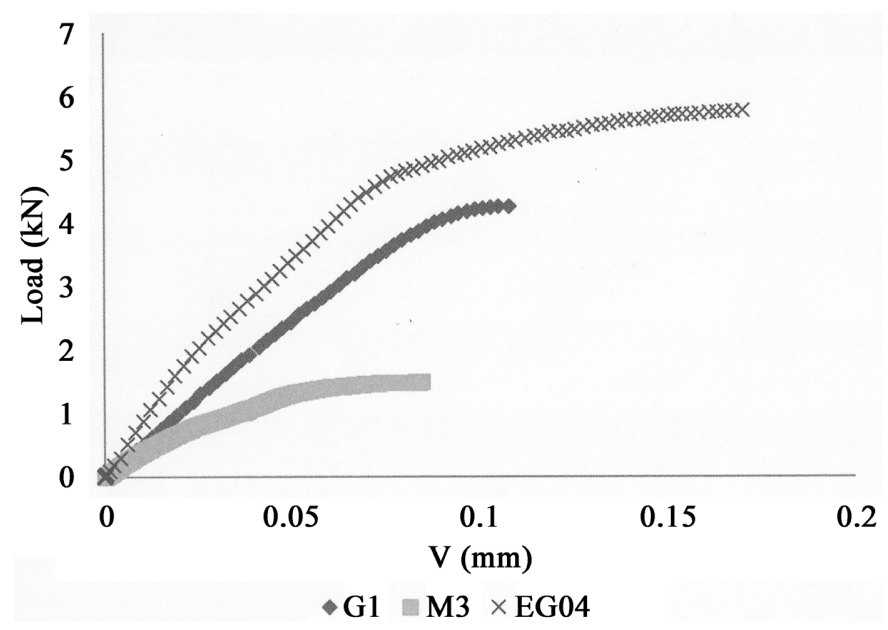

Figure 15. Load vs specimen's displacement curve ( $E G, G$ and $M$ specimen's).

OA lowering the slope by $5 \%$, obtaining $\mathrm{OP}_{5}$, which determines the $\mathrm{PQ}$ value. The $P_{\max } / P_{Q}$ ratio must be lower than 1.10 in order that the $K_{Q}$ temporary critical stress intensity factor value be $K_{I C}$, otherwise, a valid $K_{I C}$ critical stress intensity factor will not be obtained.

From previous curves, the value obtained by $K_{Q}$ assay is assessed and analyzed in accordance with ASTM E399-05 standard regarding compliance with the parameters and making $K_{Q}=K_{I C}$ as toughness of the material assayed, ref. [2]. For the analysis, fracture toughness values $K_{I C}$ were converted into critical crack opening displacement (CTOD o $\delta_{I C}$ ), Table 5, through Equation (2), and the Figure 17 clearly shows a tendency towards decrease of fracture toughness.

$$
\delta_{\text {IC }}=\frac{K_{I C}^{2}}{\sigma_{Y S} E}
$$


A fractographic study for this case was made with a scanning electron microscope (SEM), with no special preparation of fractured samples. 130, 250, 400, $1300,1900,3500 \times$ magnifications were used, digitalized in pictures in gray. Once the pictures were obtained with the SEM, the fracture surface was examined,

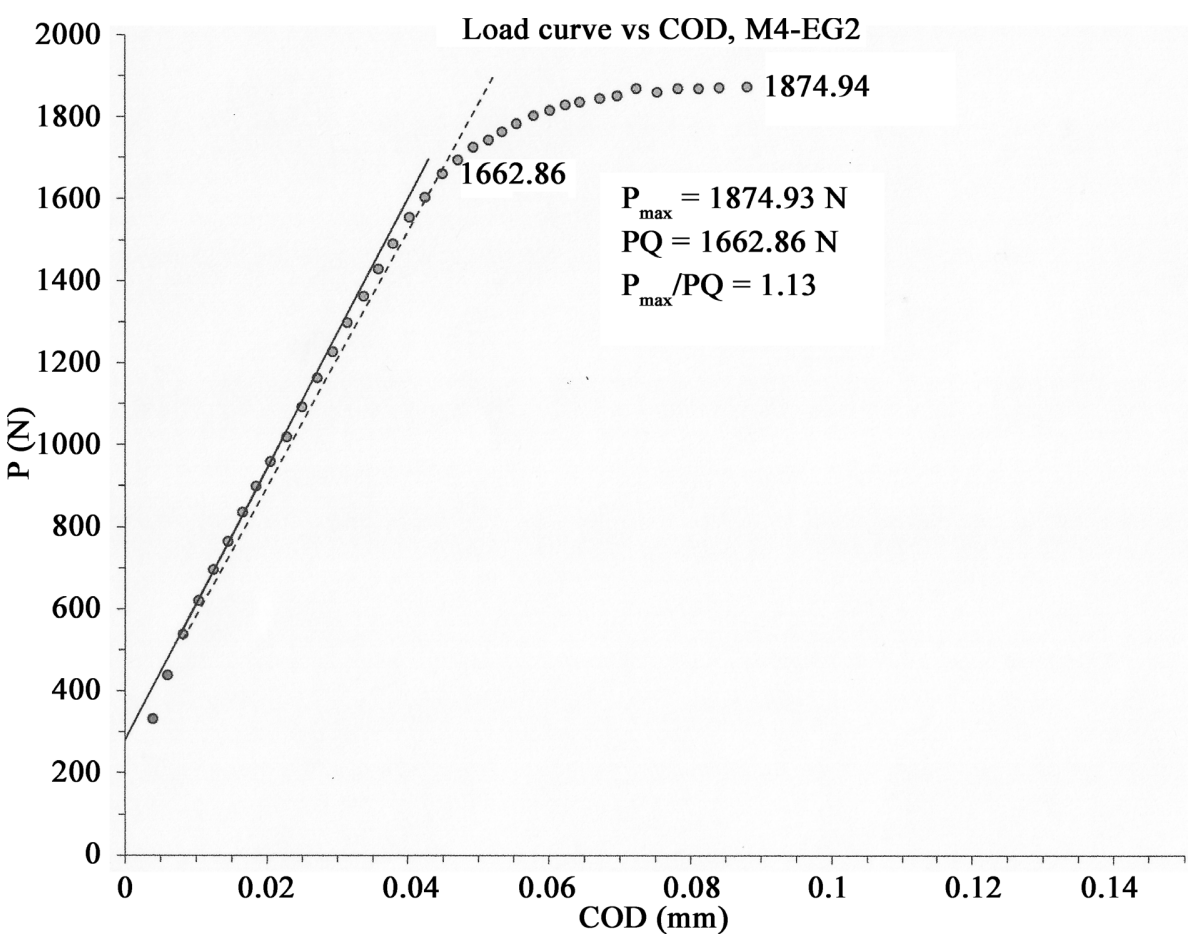

(a)

5000

Load curve vs COD, G1

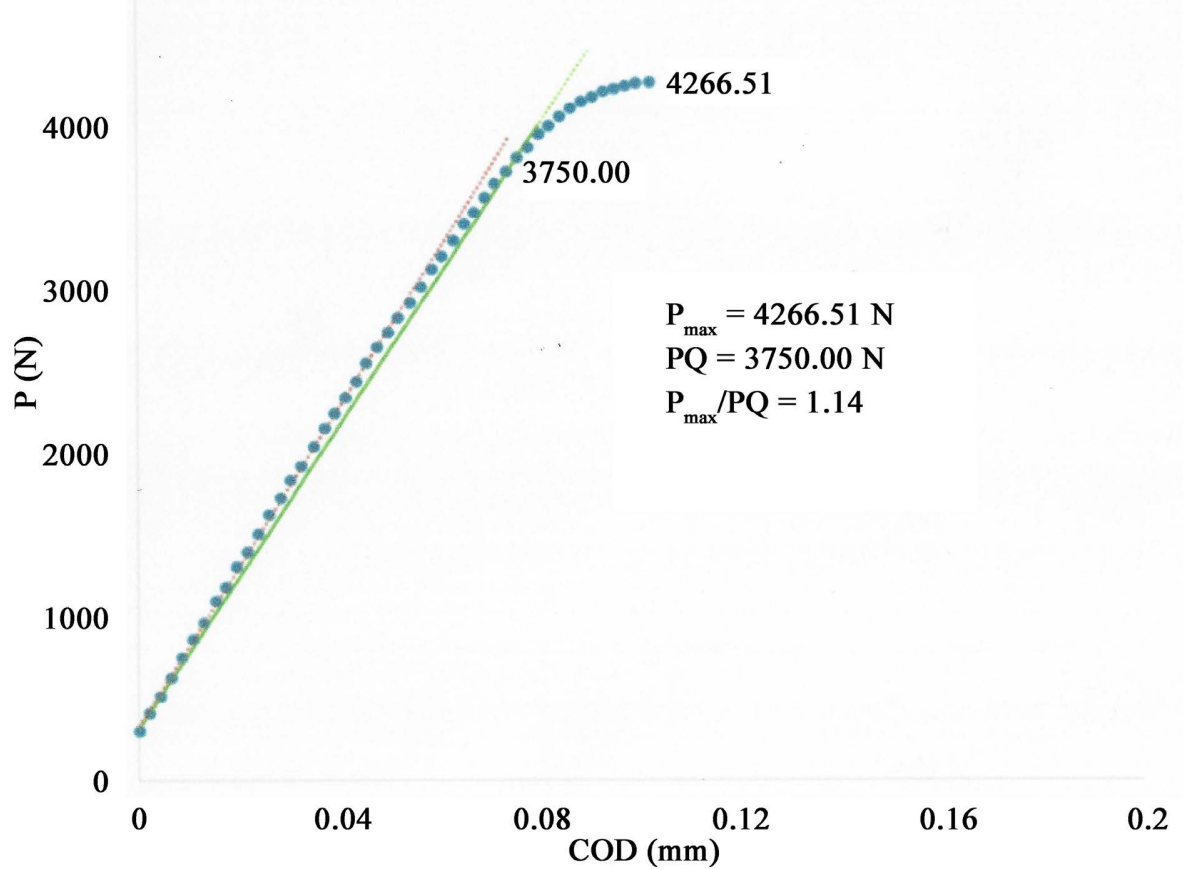

(b) 


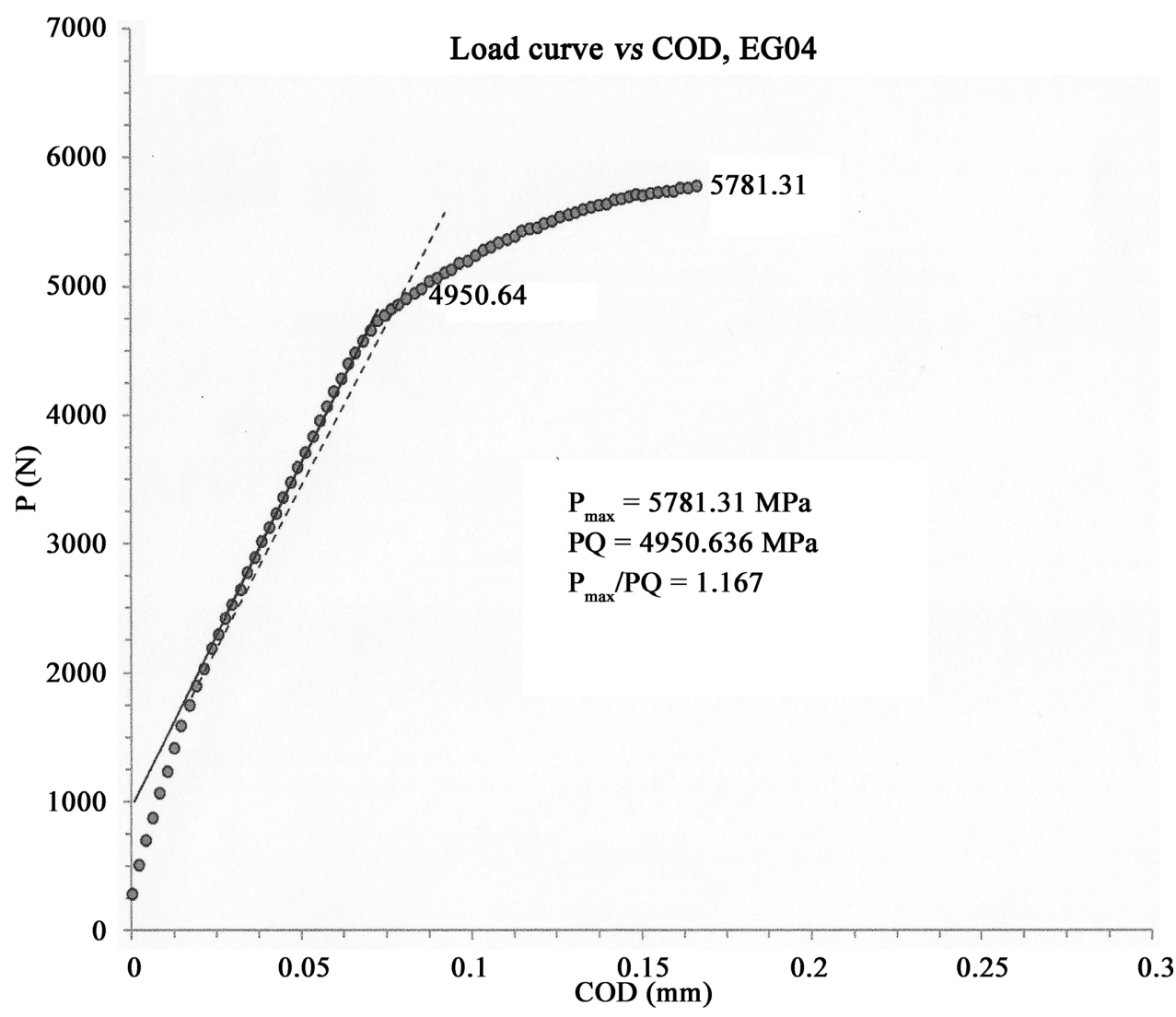

(c)

Figure 16. (a) Load vs COD curve, M4-EG2 specimen; (b) Load vs COD curve, G1 specimen; and (c) Load vs COD curve, EG04 specimen.

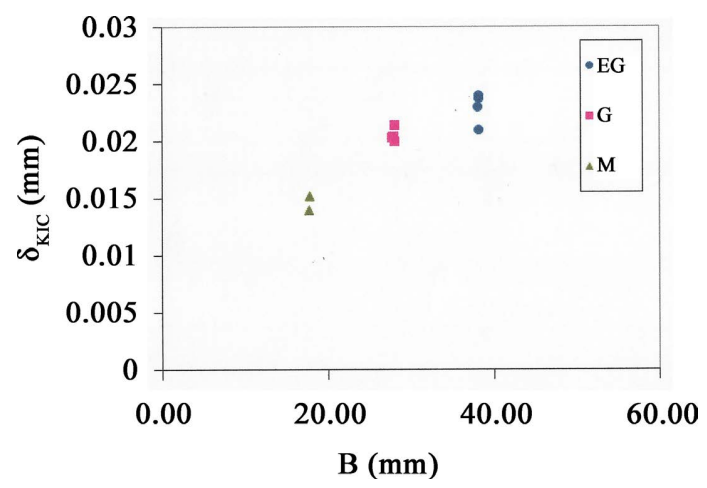

Figure 17. Fracture toughness $\left(\delta_{K I C}\right) v s$ thickness of specimen (B).

which showed a fragile failure with well-defined cleavage planes, Figure 18. Synthesizing, cleavage goes along the characteristic plane with low or no plastic strain, as well as detection of pores and micro pores present in the tearing failure section.

\subsection{Crack Length a}

The fatigue crack length $a$ is obtained from the failure face of the assayed specimen. Three measurements were made at: $1 / 4,1 / 2$ and $3 / 4$ from the failure sec- 
tion to obtain an average, which is the actual value of the fatigue crack length. These values are shown in Table 5. Sections of the failure surface were digitalized and the corresponding measurements were made with the image analyzer. Figure 19 shows the failure surface. The macroscopic exam of fatigue broken pieces reveals fracture surfaces generally plane, as for a comparatively small plastic strain, with detection lines known as benchmarking. These marks are attributable to several periods in the growth of fissures and are usually curved, with the curve radius origin at the starting point, ref. [11]. The parabolic crack length may be observed, which shows it was properly propagated.

As it is known, casting properties are determined by the composition of the alloy and the technological aspects of the casting process. Among the most important casting properties are liquid fluidity and contraction, associated with hot cracking, to tendency to create porosities due to contractions and micro segregation.

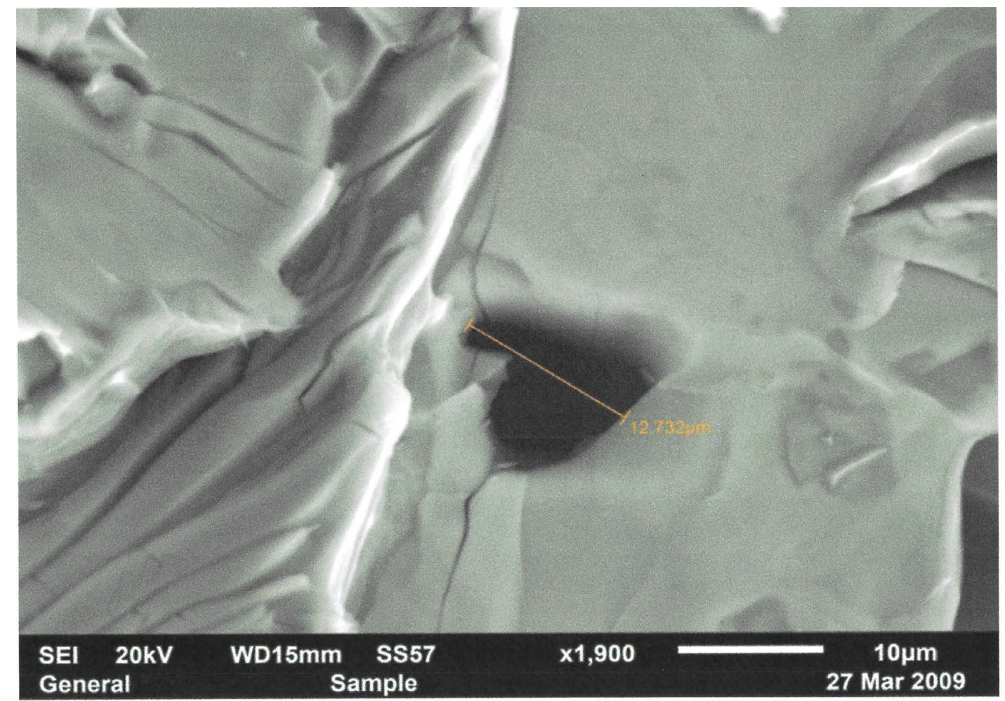

Figure 18. Cleavage plane and pore observed with $1900 \times$ objective.

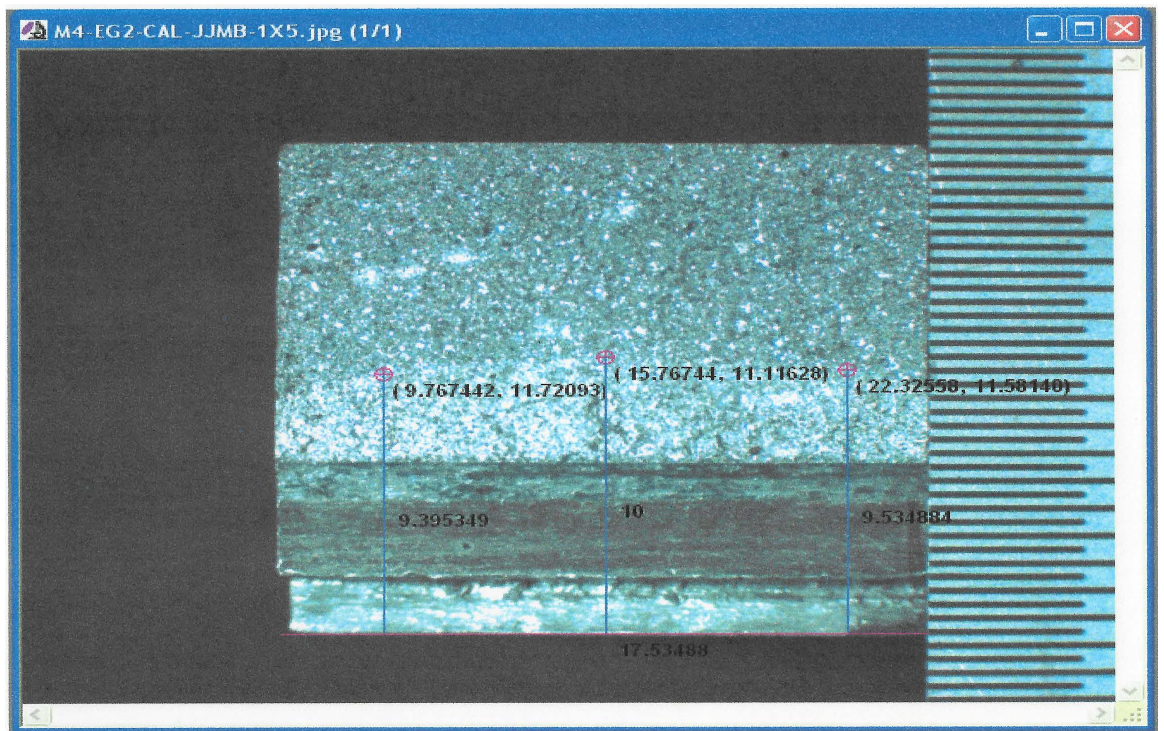

Figure 19. Failure surface analyzed, small specimen. 
Based on the latter, the pores of metallographic samples were quantified in the Olympus PMG3 inverted metallographic microscope, and photographs were taken with $5 \times$ and $20 \times$ objectives. Then, they were analyzed using the Image Pro Plus software to determine the percentage of pore for each sample studied, Figure 20. With data obtained, pores were quantified to obtain the volume of pores fraction with the following equation 3, and the Table 6 shows the results of the pore analysis of five metallography's studied.

$$
V v=\frac{\sum A \propto}{A_{T}}
$$

Based on the above, it can be observed that a quarter of load is required to break a small specimen, compared to a standard or large specimen, which may be an advantage if there is only a low-capacity machine to carry out the test. The shape of the curve is as expected from a valid test, that is, a linear starting portion followed by a curve with a maximum as is shown in Figure 15. The average toughness of the large specimens $(E G)$ was $10.616 \mathrm{MPa} \sqrt{m}$, which compared to the smaller ones $(M)$ shows a $17.5 \%$, difference, and with the medium size $(G)$ is $5.5 \%$. Figure 17 shows a clear tendency towards fracture toughness decrease as the size of the specimen is smaller, probably due to the fact that the parameter that most influences toughness is the ligament of the specimen, ref. [12]. Finally,

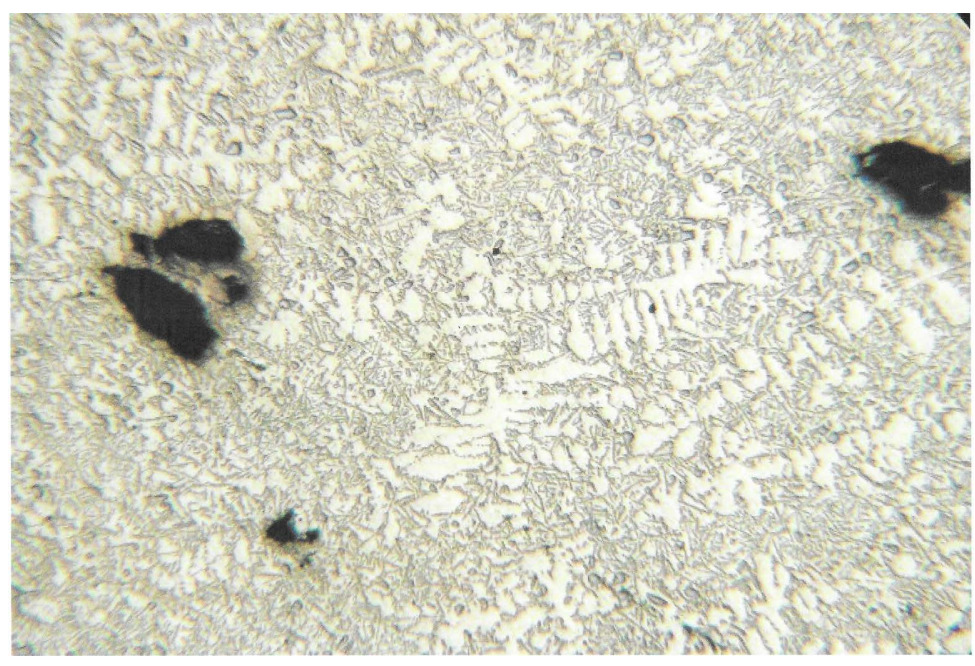

Figure 20. Photograph with $5 \times$ objective, presence of pores in A413 alloy.

Table 6. Volume of pores fraction.

\begin{tabular}{cccc}
\hline Sample & $\sum A \propto(\mu \mathrm{m})$ & $\mathrm{AT}(\mu \mathrm{m})$ & $\mathrm{Vv}$ \\
\hline $1 \mathrm{~A}$ & 0.072 & 0.621 & 0.115 \\
$2 \mathrm{~B}$ & 0.042 & 0.621 & 0.068 \\
3C & 0.023 & 0.621 & 0.037 \\
$4 \mathrm{~B}$ & 0.018 & 0.621 & 0.029 \\
$5 \mathrm{~A}$ & 0.157 & 0.621 & 0.253 \\
\hline
\end{tabular}


we consider that the hypothesis that the smaller the specimen the higher the fracture toughness will be is not valid. No problem in propagation of the crack was observed, all the specimens showed the extension of the crack in a parabolic manner, which allowed the considering as valid fracture mechanics testing.

\section{Conclusions}

Smaller specimens have lower fracture toughness than larger specimens. While an increase of fracture toughness as the size of the specimens was smaller was expected, the contrary effect was observed, probably due to the effect of the ligament of the specimen, microstructure, content, and distribution of pores present in the aluminum casting. This means that a very systematic study is required to determine the statistical distribution and critical size of pores present in A413 aluminum, in addition to obtain a specimen scaling factor.

It has been proven that, for the fracture mechanics and toughness in the fractographic study carried out with the scanning electron microscope with no special preparation of fractured samples, they showed fragile failure with well-defined cleavage planes. Cleavage goes along the characteristic plane with low or no plastic strain, as well as detection of pores and micro pores present in the tearing failure section.

The second column of Table 6 shows the summation of pores per sample; the third column shows the total area of the sample; and the last column shows the volume fraction influenced by pores, where it may be observed that the accumulation of those is higher for $1 \mathrm{~A}$ and $5 \mathrm{~A}$ samples. These are in the external section of the ingot from which samples were extracted, which shows the effect of the pores in variability of mechanical properties.

\section{Acknowledgements}

This article its corresponding research was carried out, in part, with the research projects IPN SIP-20196119. The authors thank to the reviewers for carefully reading the paper and for their constructive comments and suggestions which have improved the paper.

\section{Conflicts of Interest}

The authors declare no conflicts of interest regarding the publication of this paper.

\section{References}

[1] Doblare Castellano, M. and García Villa, L. (1988) Fundamentos de la elasticidad lineal. Síntesis, S. A. (Ed.) (in Spanish) ISBN Digital: 9788499583624.

[2] ASTM International (2005) Standard Test Method for Linear-Elastic Plane-Strain Fracture Toughness KIC of Metallic Materials. US Patent No. ASTM E399-05, West Conshohocken. https://www.astm.org/ https://doi.org/10.1520/E0399-05

[3] San Millón, F.J., Armendáriz, I., García Martinez, J., Salamanca, A. and Martin de la 
Escalera, F. (2008) Simulación por Elementos Finitos del Comportamiento en Tolerancia al daño de Estructuras Aeronáuticas. 8vo Congreso Iberoamericano de Ingeniería Mecánica. (in Spanish) Virtual Book ISBN:978-9972-2885-3-1.

[4] Wahab, M.A. and Alam, M.S. (2003) The Effect of Torsional Interaction of a Circular Porosity and a Solidification Crack on Fatigue Crack Propagation Life of ButtWelded Joints. The $10^{\text {th }}$ Annual International Conference on Composites/Nano Engineering, New Orleans, 20-26 July 2003, 753-754.

[5] Arana, J.L. and González, J.J. (2002) Mecánica de Fractura. Editorial universidad del País Vasco, p. 250. (in Spanish) ISSN: 84-8373-455-9.

[6] Davis J.R. (1993) ASM Specialty Handbook-Aluminum and Aluminum Alloys. ASM International, Almelle, p. 784.

[7] ASTM International (2015) Standard Test Methods for Tension Testing Wrought and Cast Aluminum- and Magnesium-Alloy Products (Metric). US Patent No. ASTM B557M-15, West Conshohocken. https://www.astm.org/ https://doi.org/10.1520/B0557M-15

[8] Chen, S., Chen, H., Yang, M., Chen, T. and Guo, K. (2016) Analysis on Fracture Mechanics of Unstable Rock. World Journal of Engineering and Technology, 4, 6975. https://doi.org/10.4236/wjet.2016.43C009

[9] ASTM International (2015) Standard Practice for Linear-Elastic Plane-Strain Fracture Toughness Testing of Aluminum Alloys. US Patent No. ASTM B645-10, West Conshohocken. https://www.astm.org/ https://doi.org/10.1520/B0645-10R15

[10] Gonzales Velázquez, J.L. (1998) Mecánica de Fractura Bases y Aplicaciones. Primera edición, México. (in Spanish) ISBN: 968-18-5544-2.

[11] Alcalá Cabrelles, J., Llanes Pitarch, L. M, Mateo García, A.M. and Salon Ballesteros, M.N. (2002) Fractura de Materiales. Editorial Universidad Politécnica de Catalunya, Barcelona. (in Spanish) ISBN: 9788498801378. http://hdl.handle.net/2099.3/36175

[12] Wallin, K. (1985) The Size Effect in KIC Results. Engineering Fracture Mechanics, 22, 149-163. https://doi.org/10.1016/0013-7944(85)90167-5 